\title{
Thrombotic microangiopathy-kidneys and beyond: historic lessons
}

\begin{abstract}
Abbreviations: TTP, thrombotic thrombocytopenic purpura; TMA, thrombotic microangiopathy; HUS, hemolytic uremic syndrome; MAC, membrane-attack-complex; vWF, von willebrand factor
\end{abstract}

\section{Editorial}

The first description of the condition, belonging to the continuum of thrombotic microangiopathies, was published 1924, when Moschcowitz reported a case of acute febrile anemia with petechiae, renal involvement and hyalin thrombosis of the terminal arterioles and capillaries in adolescent girl. ${ }^{1,2}$ The next case, reported by Baehr and co-workers in 1936, presented with reticulocytosis and thrombocytopenia in addition to severe anemia. ${ }^{3}$ In 1947 Singer and co-workers suggested the name "Thrombotic thrombocytopenic purpura" (TTP) to describe similar cases, published next decade. ${ }^{4}$ In 1950 Gore described the histology pattern in TTP as disseminated arteriolar and capillary platelet thrombosis, and Symmers in 1952 introduced the term "thrombotic microangiopathy" (TMA) for this pattern of injury. ${ }^{5,6} \mathrm{~A}$ few years later, in 1955, Belnap and O'Donnely found that most severe cases of epidemic diarrhea, induced by specific strain of $E$ Coli in children, were associated with purpura, anuria, and neurologic signs. Autopsy material revealed thrombosis of capillary and precapillary arterioles in lungs, liver, brain, and kidneys, as well as glomerular tuft occlusion by fibrin thrombi.?

Same year Gasser and co-workers reported bilateral necrosis of the renal cortex in acute acquired hemolytic anemia in children, and named it "Hemolytic-uremic syndrome" (HUS). ${ }^{8}$ The syndrome, described by Gasser, was in most respects similar to that was reported by Moschcowitz and Baehr and later named TTP, nevertheless he considered HUS different from TTP because of the presence of severe renal failure. However, further it was shown by Habib in 1967 and Fong with co-authors in 1982, that the fundamental pathologic lesion -TMA, is identical in HUS and TTP, although it can preferentially involve different organs. ${ }^{9}{ }^{10}$ It was described also that patients with clinical diagnosis of HUS can manifest with neurologic involvement, and a high percentage of patients, classified as having TTP, had renal failure. Moreover, individual patients have been reported as having HUS in one episode and TTP during another. ${ }^{11-16}$

This paradox aroused because the pathogenesis of TTP and HUS at that time remained unexplained, despite some facts, which later gave a clue, were already cumulated. In 1965 a combination of hemolytic anemia and azotemia was described in concordant monozygous twins, and since that time, familial HUS has been reported in children, and, infrequently, in adults, with both autosomal dominant and recessive patterns of inheritance. ${ }^{17,18}$ In 1970-th it was found, that early complement components in patients with HUS may be reduced, but terminal membrane-attack-complex (MAC) of complement generally is spared. It was also shown that patients with HUS, who have low C3 levels have high levels of activated complement components, including C3b, C3c, and C3d. Deposits of C3, found in glomeruli and arterioles, consistent with the activation of complement and local C3 consumption, and C9 staining in glomeruli and small arteries with
Volume 4 Issue I - 2017

\author{
Elena $\vee$ Zakharova \\ Department of Nephrology, City Clinical Hospital n. a. S. P. \\ Botkin, Russia
}

\begin{abstract}
Correspondence: Elena $\vee$ Zakharova, State University of Medicine and Dentistry, City Clinical Hospital n.a. S.P. Botkin, I I5284, 2nd Botkinsky proezd, 5, Moscow, Russia, Tel 7499728 8291, Email helena.zakharova@gmail.com
\end{abstract}

Received: June 22, 2017 | Published: December 15, 2017

intimal proliferation and thrombosis documents activation up to the terminal lytic MAC. ${ }^{19-26}$ Same period the role for abnormalities in von Willebrand factor (vWF) metabolism and interaction between platelets and large vWF multimers was suggested in the pathogenesis of HUS/TTP. ${ }^{27-30}$

In the early 1980-th it was found that $E$ coli of certain strains produce Shiga-like cytotoxins, E. coli O157:H7 produces Shigalike toxin/verotoxin, causes haemorrhagic colitis, and is associated with sporadic cases of "classical", or so called diarrhea associated (D+) HUS of children, thereby the link between Shiga-like toxin (Stx)-producing E Coli and D+HUS was established. ${ }^{31-33}$ To this end in 1983 Wardle, revising TMA's, described HUS and TTP as distinct entities. ${ }^{34}$ However, basing on the overlap in clinical signs and symptoms and common pathology of TTP and HUS, Remuzzi, discussing these issues in 1987, declared: "In the absence of criteria, that can differentiate between HUS and TTP, I favor the view that these term describe different clinical expressions of the same disease, a disease, characterized by microangiopathy, hemolytic anemia, renal failure and, sometimes, neurologic involvement. A diagnosis of this disease, which I shall term HUS/TTP, should be entertained whenever acute hemolytic anemia of the microangiopathic type is associated with thrombocytopenia and any degree of renal damage". ${ }^{35}$

The new facts were accumulated next decade, and at the turn of millennium became clear, that most cases of HUS (including more than $90 \%$ of those in children) are secondary to infection with Escherichia coli serotype 0157:H7 and some others, which produce Stx. Term D+ HUS therefore was replaced by the term Shiga-toxin Escherichia coli (STEC) associated HUS. It was found, however, that HUS may be associated also with several other bacteria, such as Streptococcus pneumonia; and approximately $10 \%$ of cases of the hemolytic-uremic syndrome were classified as diarrhea-negative/ non-diarrhea-associated HUS (D- HUS). Later on the term atypical HUS (aHUS) was introduced to distinguish cases not caused by either Stx-producing bacteria or streptococci. ${ }^{36-38}$ Genetic abnormalities in several complement system proteins have been documented in the familial form of aHUS: loss-of-function mutation in a regulatory gene of Factor $\mathrm{H}$ and Factor I, or a gain-of-function mutation in an effector gene of Factor B or C3. In addition to genetic abnormalities, a functional deficiency in complement Factor $\mathrm{H}$ may result from 
antibodies to the complement, resulting in acquired TMA. ${ }^{39,40}$ Sporadic cases of aHUS were described in association with infection with the human immunodeficiency virus, cancer, organ transplantation, pregnancy, and the use of certain drugs. ${ }^{41}$

At the same time the role of the protease, cleaving the ultra-large vWF (ULvWF) multimers and preventing inappropriate platelet adhesion and thrombosis, was demonstrated. In the absence of this protease ULvWF are not cleaved, causing intravascular platelet thrombosis of TTP. This protease was identified as A Disintegrinlike And Metalloprotease with a ThromboSpondin type 1 motif 13 (ADAMTS13); the gene for vWF-cleaving protease ADAMTS13 was mapped to chromosome $9 \mathrm{q} 34$ and 12 mutations in patients with TTP were identified; and the role of anti-ADAMTS13 antibodies that inhibit the proteolytic activity of ADAMTS13 in acquired TTP was confirmed. Based on these findings the concept of TTP as state of dysfunction or deficiency in ADAMTS13, was accepted. ${ }^{42-46}$

With that knowledge of aHUS and TTP pathogenesis mechanisms in mind, Tsai in 2003 postulated: "The term TTP/HUS should be avoided because it obscures differences among the various types of TMA" ${ }^{47}$ During the last decade huge progress in the understanding of molecular mechanisms of STEC-HUS, aHUS, TTP and other forms of TMA was made; the role of genetic abnormalities, autoimmunity, and infection and their interactions was demonstrated; and several classification systems of TMA were proposed. One suggests that we have to distinguish only TTP, STEC-HUS and aHUS (which include all other forms of TMA), others more accurate address the pathogenesis, distinguish primary and secondary TMA forms or syndromes. ${ }^{48-52}$

Primary TMA syndromes include:

I. Hereditary disorders (hereditary TTP; hereditary complement-mediated TMA/aHUS; and hereditary metabolic and coagulation defects with TMA).

II. Acquired disorders (autoimmune TTP; autoimmune complement-mediated TMA/aHUS; STEC-HUS; and drugmediated TMA).

III. Common disorders, associated with TMA include:

IV. Severe infections

V. Systemic cancer

VI. Severe preeclampsia, eclampsia and HELLP-syndrome.

VII. Autoimmune disorders (systemic lupus erythematosus, systemic sclerosis, and antiphospholipid syndrome).

VIII. Hematopoetic stem-cell and organ transplantation.

The key point in the diagnosis of TMA as a first step is to evaluate clinical signs and symptoms. TMA is diagnosed in presence of thrombocytopenia, microangiopathic hemolysis (negative Coombs test, shystocytosis, reticulocytosis, elevated LDH, low haptoglobin) and severe organ/multiorgan damage. As a second step, differential diagnostics of primary TMA syndromes and common TMAassociated disorders demand careful evaluation of current illness and family history, concurrent diseases, drug history, coagulation tests, autoimmune screening, serum complement levels, stools for STEC and ADAMTS13 plasma activity test. Accurate diagnosis guides proper treatment for TMA-associated life-threatening conditions, which currently available for many TMA syndromes, including aHUS and TTP.

\section{Acknowledgements}

None.

\section{Conflicts of interest}

The author declares there is no conflict of interest.

\section{References}

1. Moschcowitz E. Hyaline thrombosis of the terminal arterioles and capillaries: a hitherto undescribed disease. Proc N Y Pathol Soc. $1924 ; 24: 21-24$

2. Moschcowitz E. An acute febrile pleiochromic anemia with hyalin thrombosis of the terminal arterioles and capillaries. Arch Intern Med. 1925;36(1):89-93.

3. Baehr G, Klemperer P, Schifrin A. An acute febrile anemia and thrombocytopenic purpura with diffuse platelet thrombosis of capillaries and arterioles. Trwts Assoc Am Physicians. 1936;51:43-58.

4. Singer K, Bornstein FP, Wile SA. Thrombotic thrombocytopenic purpura. Hemorrhagic diathesis with generalized platelet thromboses. Blood. 1947;2(6):542-554

5. Gore I. Disseminated arteriolar and capillary platelet thrombosis, a morphologic study of its histogenesis. Am J Pathol. 1950;26(1):155-175.

6. Symmers WS. Thrombotic microangiopathic haemolytic anemia (thrombotic microangiopathy). Br Med J. 1952;2(4790):897-903.

7. Belnap W, O’Donnell J. Epidemic gastroenteritis due to Escherichia coli 0-111; a review of the literature, with the epidemiology, bacteriology, and clinical findings of a large outbreak. J Pediatr. 1955;47:178-183.

8. Gasser C, Gautier E, Steck A, et al. Hemolytic-uremic syndrome: bilateral necrosis of the renal cortex in acute acquired hemolytic anemia. Schweiz Med Wochenschr. 1955;85(38-39):905-909.

9. Habib R, Mathieu H, Rover P. Le syndrome haemolytique et uraemic de l'enfant. Nephron. 1967;4:139-172.

10. Fong JS, De Chadarevian JP, Kaplan BS. Hemolytic-uremic syndrome. Current concepts and management. Pediatr Clin North Am. 1982;29(4):835-856.

11. Shumway CN, Miller G. An unusual syndrome of hemolytic anemia, thrombocytopenic purpura and renal disease. Blood. 1952;12(12):10451060 .

12. MacWhinney JB, Packer JT, Miller O. Thrombotic thrombocytopenic purpura in childhood. Blood. 1962;19:181-199.

13. Dunea G, Muehrcke RC, Nakamoto S, et al. Thrombotic thrombocytopenic purpura with acute anuric renal failure. Am J Med. 1966;41(6):1000-1006.

14. Gianantonio CA, Vitacco M, Mendilarzu F. The hemolytic-uremic syndrome. Nephron. 1973;11:174-192.

15. Eknoyan G, Riggs SA. Renal involvement in patients with thrombotic thrombocytopenic purpura. Am J Nephrol. 1986;6(2):117-131.

16. Sheth KJ, Swich HM, Haworth N. Neurologic involvement in hemolyticuremic syndrome. Ann Neurol. 1986;19(1):90-93.

17. Campbell S, Carré IJ. Fatal haemolytic uraemic syndrome and idiopathic hyperlipaemia in monozygotic twins. Arch Dis Child. 1965;40:654-658.

18. Kaplan BS, Chesney RW, Drummond KN. Hemolytic uremic syndrome in families. N Engl J Med. 1975;292:1090-1093.

19. Cameron IS, Vick R. Plasma C3 in hemolytic-uremic syndrome and thrombotic thrombocytopenic purpura [letter]. Lancet. 1973;2(7835):975.

20. Kaplan BS, Thomson PD, MacNab GM. Serum complement levels in haemolytic-uraemic syndrome. Lancet. 1973;2:1505-1556. 
21. Monnens L, Hendrickx U, Van Weiringen P. Serum complement levels in haemolytic-uraemic syndrome. Lancet. 1974;2:294-301.

22. Stuhlinger W, Kourilsky O, Kanfer A, et al. Letter: Haemolyticuraemic syndrome: evidence for intravascular C3 activation. Lancet. 1974;2(7883):788-789.

23. Kim Y, Miller K, Michael AF, et al. Breakdown products of $\mathrm{C} 3$ and factor B in hemolytic-uremic syndrome. J Lab Clin Med. 1977;89(4):845-850.

24. Barre P, Kaplan BS, de Chadarevian JP, et al. Hemolytic uremic syndrome with hypocomplementemia, serum $\mathrm{C} 3 \mathrm{NeF}$, and glomerular deposits of C3. Arch Pathol Lab Med. 1977;101(7):357-361.

25. Carreras L, Romero R, Requesens C, et al. Familial hypocomplementemic hemolytic uremic syndrome with HLA-A3,B7 haplotype. JAMA. 1981;245(6):602-604.

26. Monnens L, Molenaar J, Lambert PH, et al. The complement system in hemolytic-uremic syndrome in childhood. Clin Nephrol. 1980;13(4):168171.

27. Hoyer JR, Michael AF, Hoyer LW. Immunofluorescent localization of antihemophylic factor antigen and fibrinogen in human renal diseases. $J$ Clin Invest. 1974;53(5):1375-1384.

28. Moake JL, Rudy CK, Troll JH, et al. Unusually large plasma factor VIII:von Willebrand factor multimers in chronic relapsing thrombotic thrombocytopenic purpura. N Engl J Med. 1982;307(23):1432-1435.

29. Kelton JG, Moore J, Santos A, et al. The detection of a plateletagglutinating factor in thrombotic thrombocytopenic purpura. Ann Intern Med. 1984;101(5):589-593.

30. Moake JL, Brynes II, Troll JH, et al. Abnormal factor VIII: von Willebrand factor patterns in the plasma of patients with hemolytic uremic syndrome. Blood. 1984;64(3):592-598.

31. O'Brien AD, La Veck GD, Thompson MR, et al. Production of Shigella dysenteriae type 1-like cytotoxin by Escherichia coli. J Infect Dis. 1983;146(6):764-769.

32. Riley LW, Remis RS, Helgerson SD, et al. Hemorrhagic colitis associated with a rare Escherichia coli serotype. $N$ Engl J Med. 1983;308(12):681685 .

33. Karmali MA, Steele BT, Petric M, et al. Sporadic cases of haemolyticuraemic syndrome associated with faecal cytotoxin and cytotoxinproducing Escherichia coli in stools. Lancet. 1983;1(8325):619-620.

34. Wardle EN. Thrombotic microangiopathy [letter]. Clin Nephrol. 1983;20:323.

35. Remuzzi G. HUS and TTP: Variable expression of a single entity. Kidney Int. 1987;32(2):292-308

36. Kaplan BS, Meyers KE, Schulman SL. The pathogenesis and treatment of hemolytic uremic syndrome. J Am Soc Nephrol. 1988;9(6):1126-1133.

37. Constantinescu AR, Bitzan M, Weiss LS, et al. Non-enteropathic hemolytic uremic syndrome: causes and short-term course. Am J Kidney Dis. 2004;43(6):976-982.

38. Noris M, Remuzzi G. Hemolytic uremic syndrome. J Am Soc Nephrol. 2005;16(4):1035-1050

39. Noris M, Brioschi S, Caprioli J, et al. Familial haemolytic uraemic syndrome and an MCP mutation. Lancet. 2003;362(9395):1542-1547.

40. Richards A, Kemp EJ, Liszewski MK, et al. Mutations in human complement regulator, membrane cofactor protein (CD46), predispose to development of familial hemolytic uremic syndrome. Proc Natl Acad Sci U S A. 2003;100(22):12966-12971.

41. Ruggenenti P, Noris M, Remuzzi G. Thrombotic microangiopathy, hemolytic uremic syndrome, and thrombotic thrombocytopenic purpura. Kidney Int. 2001;60(3):831-846.

42. Furlan M, Robles R, Solenthaler M, et al. Deficient activity of von Willebrand factor-cleaving protease in chronic relapsing thrombotic thrombocytopenic purpura. Blood. 1997;89(9):3097-3103.

43. Tsai HM, Lian EC. Antibodies to von Willebrand factor-cleaving protease in acute thrombotic thrombocytopenic purpura. $N$ Engl J Med. 1998;339(22):1585-1594.

44. Levy GG, Nichols WC, Lian EC, et al. Mutations in a member of the ADAMTS gene family cause thrombotic thrombocytopenic purpura. Nature. 2001;413(6855):488-494

45. Arya M, Anvari B, Romo GM, et al. Ultralarge multimers of von Willebrand factor form spontaneous high-strength bonds with the platelet glycoprotein Ib-IX complex: studies using optical tweezers. Blood. 2002;99(11):3971-3977.

46. Dong JF, Moake JL, Nolasco L, et al. ADAMTS-13 rapidly cleaves newly secreted ultralarge von Willebrand factor multimers on the endothelial surface under flowing conditions. Blood. 2002;100(12):4033-4039.

47. Tsai HM. Is severe deficiency of ADAMTS-13 specific for thrombotic thrombocytopenic purpura? Yes. J Thromb Haemost. 2003;1(4):625-631.

48. Coppo P, Veyradier A. Thrombotic Microangiopathies: Towards a Pathophysiology-Based Classification. Cardiovascular \& Haematological Disorders-Drug Targets. 2009;9(1):1-15.

49. Norris M, Remuzzi G. Hemolytic uremic Syndrome. $N$ Engl J Med. 2009;361:1676-1687.

50. De Serres SA, Isenring P. Renal Thrombotic Microangiopathy Revisited: When a Lesion is not a Clinical Finding. Saudi J Kidney Dis Transpl. 2010;21(3):411-416.

51. Riedl M, Orth-Höller D, Würzner R. An Update on the Thrombotic Microangiopathies. Hemolytic Uremic Syndrome (HUS) and Thrombotic Thrombocytopenic Purpura (TTP). Semin Thromb Hemost. 2004;40(4):413-415.

52. George JN, Nester CM. Syndromes of thrombotic microangiopathy. $N$ Engl J Med. 2014;371:654-666. 